\title{
UHPFRC for concrete repair
}

\author{
Alexandrine Maltais ${ }^{1}$, Nikola Petrov $^{1}$, Michel Thibault ${ }^{2 *}$, Benoit Bissonnette $^{3}$ \\ ${ }^{1}$ Béton Provincial, Québec, Canada \\ ${ }^{2}$ The St-Lawrence Seaway Management Corporation, Montréal, Canada \\ ${ }^{3}$ CRIB, Université Laval, Department of Civil and Water Engineering, Québec, Canada
}

\begin{abstract}
As part of the St. Lawrence Seaway lock maintenance, the current practice is to perform concrete repairs entirely with reinforced concrete, using either ordinary concrete or high performance concrete (HPC) mixtures. However, with the recent advances in the field of ultra-high performance fiber-reinforced concrete (UHPFRC), the use of this new material is considered in view of improving the overall performance of repairs. The goal is to implement repairs capable of dissipating a lot of energy before breaking when a ship hits a concrete lock wall. Numerous rehabilitation materials and methods have been experimented in the past. They all were unsuccessful due to inadequate shear and impact strength characteristics of the repair materials used. These needs can be efficiently fulfilled with UHPFRC, with their superior mechanical properties and very high energy-dissipation ability. To analyze the in-situ behavior of UHPFRC, two main mixture designs were investigated: a 160 -MPa mixture containing $3 \%$ of steel fibers and a $120-\mathrm{MPa}$ mixture containing $3.5 \%$ of a steel fiber blend. Thick repairs with average depths of $700 \mathrm{~mm}$ were carried out during the winter shut down period, in very harsh climatic conditions $\left(-12{ }^{\circ} \mathrm{C}\right.$, gusty wind). The performance exhibited by the repairs after a full year shows that UHPFRCs can withstand very effectively the impacts from the transiting vessels
\end{abstract}

\section{Introduction}

The use of UHPFRCs in practice is still limited today. This material is mainly used for the construction of elements with a thickness of $200 \mathrm{~mm}$ at most or for thin repairs. In contrast, when repairing lock gates of the St. Lawrence Seaway, the smallest repair dimension is of the order of half a meter.

The Great Lakes St. Lawrence Seaway System is a deep waterway that stretches over 3,700 kilometers (2,340 miles) between the Atlantic Ocean and the head of the Great Lakes in the hearth of North America. The St. Lawrence Seaway portion extends from Montreal to the middle of Lake Erie. Considered one of the great technical achievements of the $20^{\text {th }}$ century, the St. Lawrence Seaway includes 15 locks, 13 in Canada and 2 in USA, as shown in Figure 1.

Altogether, the locks are the most spectacular lifting system in the world. Ships up to 225.5 meters long (740 feet) and 23.8 meters wide (78 feet) are regularly elevated to more than 180 meters above sea level, the height of a 60 -floor building. The ships are twice longer and one and a half time wider than a football stadium and carry the equivalent of 25,000 metric tons each.
Each lock measures 233.5 meters in length (766 feet), 24.4 meters in width (80 feet) and 9.1 meters in depth (30 feet). A lock is filled using about 91 thousand cubic meters of water (24 million gallons) in just 7 to 10 minutes. The crossing of a lock takes about 45 minutes.

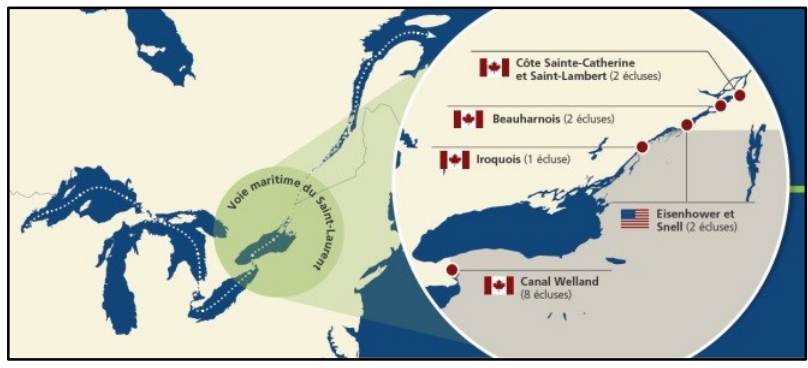

Fig. 1. Seaway Network

This network is open to navigation during the spring, summer and fall. Maintenance work on the lock walls is carried out exclusively during the winter period, which extends from late December to early March.

Repairs of the lock walls are recurrent. When ships go through the locks, the concrete walls are often hit severely. During such impacts, the energy transmitted to the surrounding concrete is considerable and causes cracking and bursting, particularly in the corners of the lock gates. Over the years, repairs using conventionally

\footnotetext{
* Corresponding author: MThibault@seaway.ca
} 
reinforced concrete (ordinary concrete, self-compacting concrete) have failed to perform satisfactorily. In January 2017, two ultra-high performance fiber reinforced concrete mixtures (UHPFRC) were used for the repair of vulnerable wall sections. The goal was to achieve repairs able to withstand several ship impacts.

\section{Development of UHPFRCs}

In the 1930s, efforts were already made towards increasing the strength of concrete. In the $1960 \mathrm{~s}$, compressive strength values up to $650 \mathrm{MPa}$ were reached on compressed samples, heat-cured under elevated pressure, demonstrating that the potential strength of Portland cement paste was under exploited [1].

Along the same lines, Pierre Richard invented reactive powder concrete (RPC) in the 1990s [1]. The idea was to reduce the size of all solid particles in the concrete and thus ensure better homogenization of the matrix. Hence, RPC does not contain coarse aggregate and the granular distribution is optimized to ensure maximum compactness. Thermal treatments are used to further reduce porosity and permeability, and thereby increase compressive strength [1]. A low w/cm $(<0.25)$, a high superplasticizer dosage, a high silica fume content, and the focus on maximum particle compaction are essential characteristics of RPCs. To fix the problem of low ductility of RPCs, metal fibers were incorporated into the matrix, leading to the development of UHPFRCs.

\section{Repairs}

In the winter of 2017,5 badly damaged areas of the Saint-Lambert lock walls near Montreal were selected for experimental repairs using UHPFRC. In Figure 2, one can see the typical geometry of the areas to be repaired.

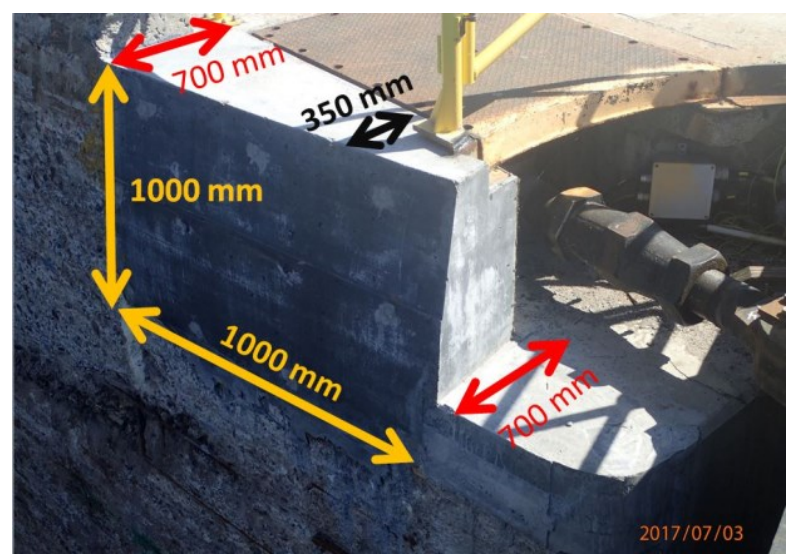

Fig. 2. Typical geometry of repairs

Figure 3 illustrates, in cross-sectional view, the local wall repair details. With an average volume of $1 \mathrm{~m}^{3}$, this type of repair is commonly performed with ordinary concrete, but quite unusual with a material such as
UHPFRC, due to the considerable cost of this material and the significant heat rise to be expected.

During execution of the concrete repair work, the outdoor temperature fell down to minus $12{ }^{\circ} \mathrm{C}$. The UHPFRC used for repairs was mixed on site using a mobile mixer, which allowed to prepare mixtures that were almost self-compacting. Placement of the UHPFRC was carried out using a bucket mounted on a loader and the material was poured directly into the formwork in less than 15 minutes after mixing. No means of consolidation (using vibrators, tamping rods or other) of the concrete was used. Once placement was completed, insulation blankets and heaters were used to prevent the fresh concrete from freezing.

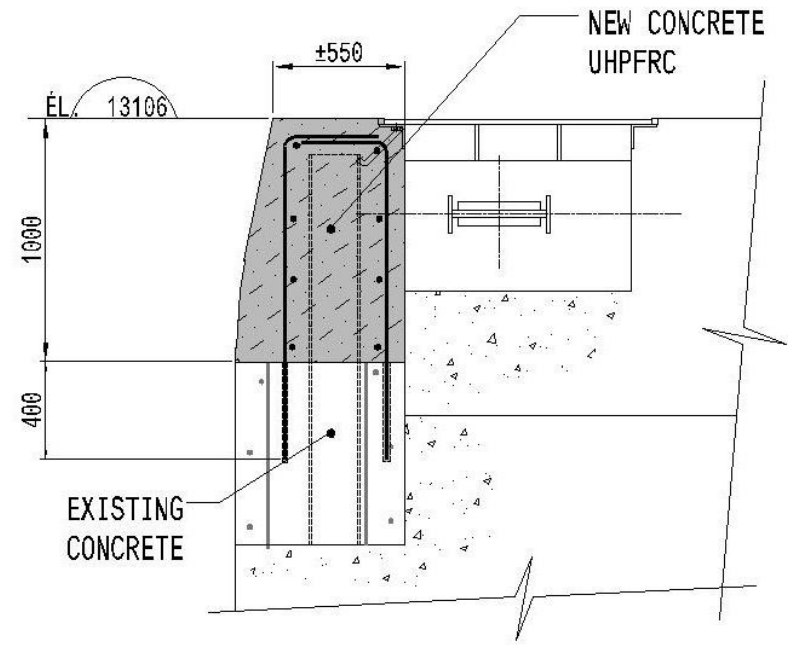

Fig. 3. Details of the repairs

\section{Mixture design}

The two main mixtures selected and characterized for the project are referred to as $160 / 3$ and $120 / 3.5$. The $160 / 3$ mixture is a typical UHPFRC, with a $\mathrm{w} / \mathrm{cm}$ of 0.19 and a cementitious materials $(\mathrm{CM})$ content of $1150 \mathrm{~kg} / \mathrm{m}^{3}$. The binder is a blended cement with $15 \%$ of silica fume. This mixture contains $3 \%$ by volume of metallic fibers, 0.2 $\mathrm{mm}$ in diameter and $13 \mathrm{~mm}$ in length. The 120/3.5 mixture was developed to better meet the project requirements, i.e. to get high tensile/flexural strengths and impact resistance, while reducing the maximum temperature developed during setting and hardening. This mixture contains $3.5 \%$ of a metallic fiber blend (dual fiber size), a cementitious materials content of 800 $\mathrm{kg} / \mathrm{m}^{3}$ and a $\mathrm{w} / \mathrm{cm}$ of 0.25 . (note: the two UHPFRC matrices have been used in some case with different fiber dosages, which are indicated by the number following the slash symbol in the mixture code)

To limit the maximum temperature reached inside the repairs, means were taken such that the initial temperature of the fresh UHPFRC would be between 8 and $10{ }^{\circ} \mathrm{C}$. This also promoted easier placement, since low temperatures help to reduce the viscosity of UHPFRCs. 


\section{Properties of the UHPFRC mixtures}

\subsection{Compressive strength}

Compressive strength tests were performed at 4 and 28 days in accordance with ASTM C109/C109M, on 50 mm cubes. After demolding at 24 hours, the cubes were kept in a controlled environment at $20 \pm 2{ }^{\circ} \mathrm{C}$ and $100 \%$ R.H. In addition to the 4-d and 28-d tests, a third series of cubes underwent accelerated curing at $90{ }^{\circ} \mathrm{C}$ for 72 hours, after what it was tempered for 24 hours and then tested for compressive strength. Three specimens were tested in each series.

Figure 4 shows the compressive strength results for all three series of samples cast for both UHPFRC mixtures. The compressive strength values recorded for the 160/3 mixture are $77 \pm 3 \mathrm{MPa}$ at 4 days, $135 \pm 1 \mathrm{MPa}$ at 28 days, and $150 \pm 6 \mathrm{MPa}$ after accelerated curing. The compressive strength values recorded for the 120/3.5 mixture are $67 \pm 3 \mathrm{MPa}$ at 4 days, $123 \pm 3 \mathrm{MPa}$ at 28 days, and $140 \pm 2 \mathrm{MPa}$ after accelerated curing.

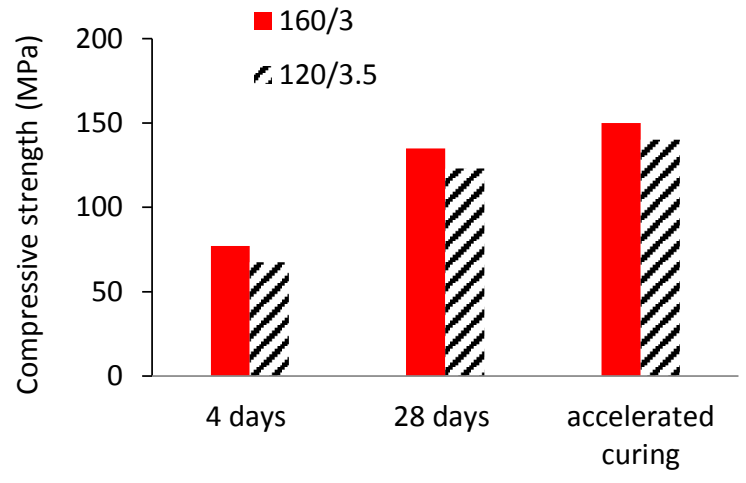

Fig. 4. Compressive strength

\subsection{Flexural strength}

Flexural strength tests were conducted in accordance with ASTM C1609 (Standard Test Method for flexural Performance of Fiber-Reinforced Concrete), using $150 \times 400 \times 50 \mathrm{~mm}$ beams cast at the job site. After demolding at 24 hours, the specimens were stored in a moist chamber kept at $23{ }^{\circ} \mathrm{C}$ until the tests were carried out at 28 days. The test beams were poured horizontally.

The flexural experiments were carried out on three specimens of each mixture using a fourth-point bending scheme, the distance between all concentrated loads being $100 \mathrm{~mm}$. The midspan deflection was recorded with a LVDT transducer referenced to the neutral axis of the specimen. The loading rate was set at $0.01 \mathrm{kN} / \mathrm{s}$.

The maximum flexural resistance was recorded upon initiation of the first crack. The average modulus of rupture (MOR) recorded on the three specimens for the $160 / 3$ mixture is $28.8 \pm 1 \mathrm{MPa}$, while the recorded one on the three specimens of the $120 / 3.5$ mixture is $26.8 \pm 2$ $\mathrm{MPa}$. Figure 5 shows the stress - deflection behaviour of single specimens during the test.

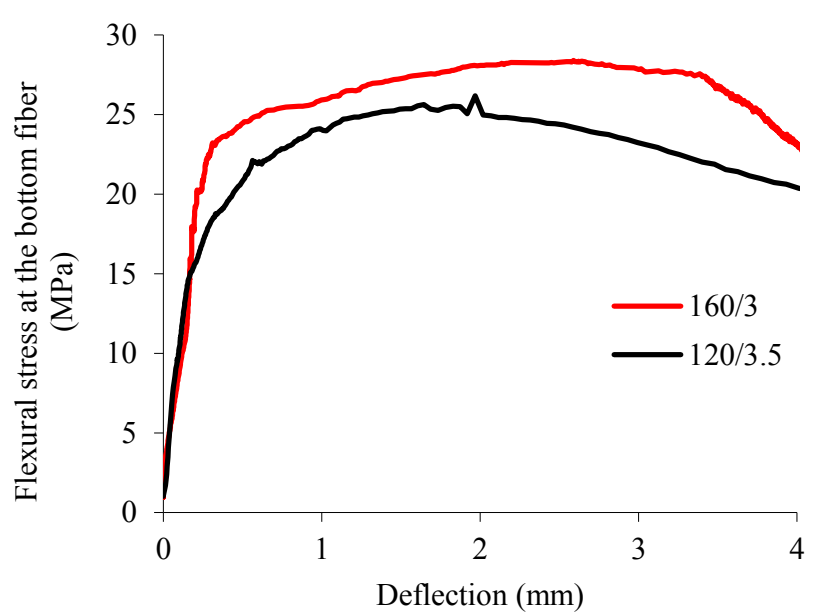

Fig. 5. Flexural test results (individual specimen)

\subsection{Direct tensile test}

Direct tensile tests were performed in accordance with SIA 2052 - Appendix D. The geometry of the test specimens, which were molded horizontally, is shown in Figure 6. After demolding at 24 hours, the specimens were kept in a moist chamber at $23{ }^{\circ} \mathrm{C}$ until the time of testing. Prior to loading, a measuring device using a LVDT was installed in the straight portion of the specimen (between reference points $\mathrm{O}$ and $\mathrm{P}$ ), as shown in Figure 7. During the tests, the loading rate was set at $0.01 \mathrm{kN} / \mathrm{s}$.

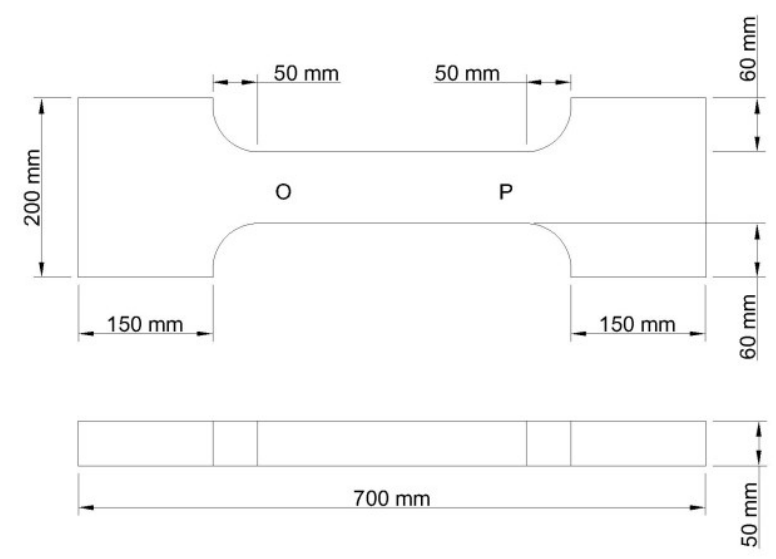

Fig. 6. Specimens used in the direct tensile test

For the $160 / 3$ mixture, the average tensile strength is $10.0 \mathrm{MPa}$ at 28 days. The results obtained from the five tested specimens show a range of $1.4 \mathrm{MPa}$ and a standard deviation of $0.5 \mathrm{MPa}$. The average tensile strength for the $120 / 3.5$ mixture is $8.0 \mathrm{MPa}$. This average is the result of 6 tests, with a range of $4.3 \mathrm{MPa}$ and a standard deviation of $1.5 \mathrm{MPa}$. Figure 8 shows typical examples of the stress-strain behaviour of single test specimens recorded in the direct tensile test. 


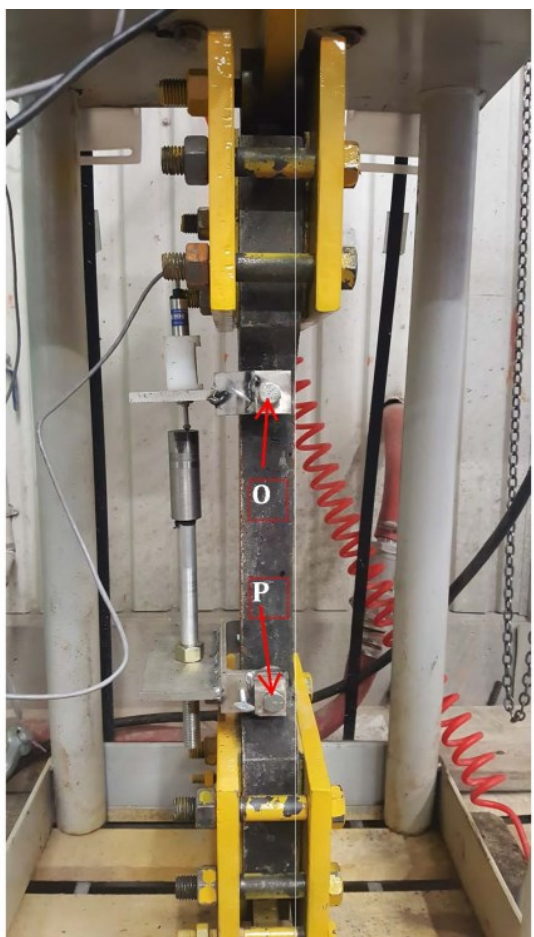

Fig. 7. Direct tensile test setup (SIA 2052)

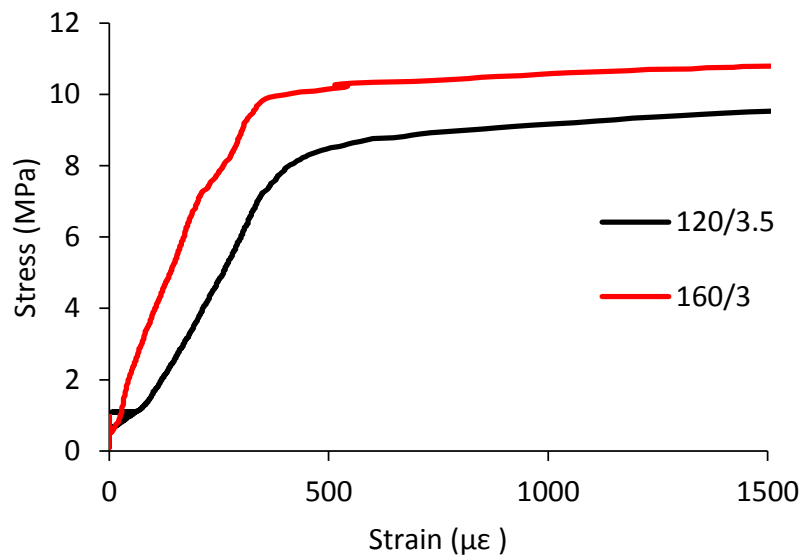

Fig. 8 Typical direct tensile test results for the two investigated UHPFRC matrices (individual specimen)

\subsection{Shrinkage}

Length change tests were performed in accordance with ASTM C157, except for the test specimen size and curing regimen. The tests were carried out on $25 \times 25 \times 280 \mathrm{~mm}$ prisms to limit the influence of the moisture gradient induced by the drying process and to ensure a rapid dissipation of the heat of hydration [2]. The samples underwent different treatments after demoulding at 24 hours, as shown in Table 1. Two prisms were tested for each of the investigated curing conditions. The measurements were made at 3, 7, 14, 21, 28 and 90 days. It should be noted that the comparison of data shown on figures 9 and 10 can be difficult to compare because different curing conditions were performed.
Tab.1. Conditioning regimes in the length change experiments

\begin{tabular}{|l|l|l|}
\hline No. & Label & Specimen conditioning \\
\hline 1 & $(\mathrm{~s})$ & $\begin{array}{l}\text { Sealed from the time of demoulding } \\
(24 \mathrm{~h})\end{array}$ \\
\hline 2 & $(4)$ & 4 days at $100 \%$ RH and $50 \%$ RH after \\
\hline 3 & $(7)$ & 7 days at $100 \%$ RH and $50 \%$ RH after \\
\hline 4 & $(14)$ & 14 days at $100 \%$ RH and $50 \%$ RH after \\
\hline
\end{tabular}

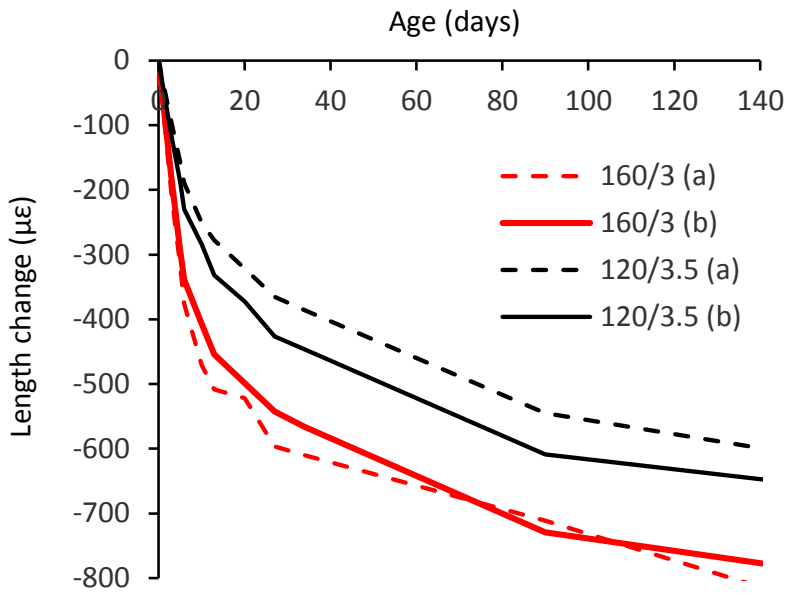

Fig. 9. Length change test results for sealed specimens (autogenous shrinkage)

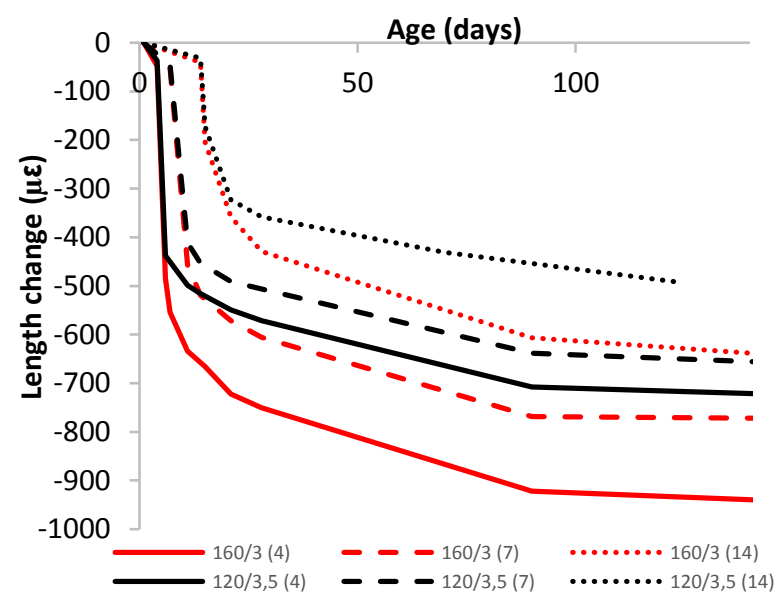

Fig. 10. Length change test results for drying specimens

The length change data recorded for the sealed specimen (autogenous shrinkage) on two prims ( $a$ and $b$ ) is shown in Figure 9. The 28-day average autogenous shrinkage values are $570 \pm 40$ and $350 \pm 40 \mu \varepsilon$ for the $160 / 3$ and $120 / 3.5$ mixtures, respectively (note: $1 \mu \varepsilon=1$ $\left.\times 10^{-6}\right)$. It takes more than 90 days to measure shrinkage to reach the value of quasi stabilization. This is due to a low W/CM of UHPFRC. It is possible that quasi stabilization has been achieved before, but with the single measurements made in time and having no measures between 28 and 90 days, it is not possible to demonstrate it, in this study.

The drying shrinkage test results are shown in Figure 10. Total shrinkage decreases for both mixtures as the wet curing duration is increased from 4 to 14 days. 
In order to evaluate the risk of cracking associated with the shrinkage of UHPFRCs and the effectiveness of fibers in preventing this risk, ASTM C1581 restrained shrinkage tests were carried out on two plain (fiber-free) mixtures, $120 / 0$ and 160/0, in addition to fiber reinforced mixtures $120 / 3.5$ and $160 / 3$. The results of the restrained shrinkage tests are shown in Figure 11.

The ASTM C1581 annular restrained shrinkage test is intended to evaluate the cracking sensitivity of a concrete mixture, essentially on a comparative basis. In accordance with the standard procedure, two rings per mixture were tested. After demolding at $24 \pm 0.5 \mathrm{~h}$, the samples were stored in a controlled environment at $23 \pm$ $2{ }^{\circ} \mathrm{C}$ and $50 \%$ R.H. Deformations inside the restraining rings were measured with strain gages and recorded every 5 minutes. Monitoring of the steel ring strains allow to determine by calculation the evolution of the average stress of the concrete and to determine the moment of cracking.

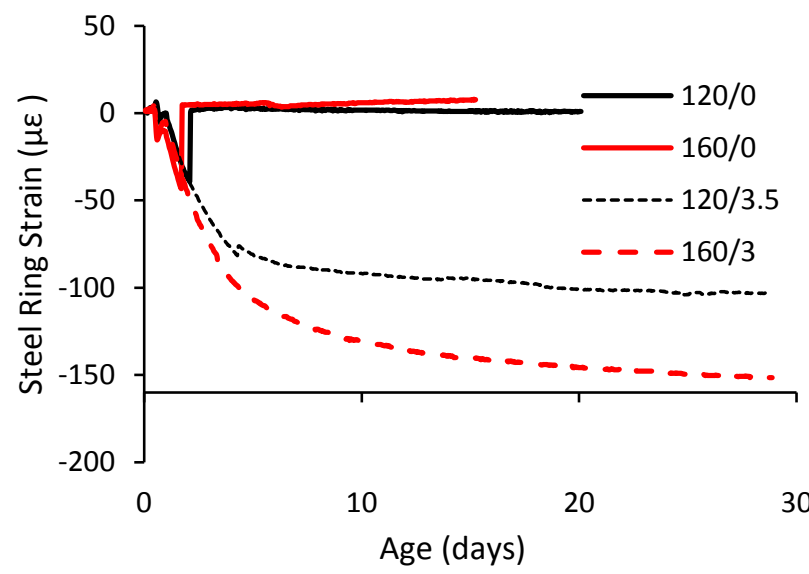

Fig. 11. Restrained shrinkage / craking behavior

The rings cast with both plain mixtures $120 / 0$ and $160 / 0$ cracked after only 36 and 48 hours, whereas the $120 / 3.5$ and 160/3 UHPFRCs rings had not cracked yet after 28 days of testing [2]. Moreover, the stress sustained in the fiber-reinforced matrices at 28 days are two to four times larger than the maximum stress recorded at cracking in the corresponding plain matrices.

\subsection{Rapid Chloride Penetration Test}

Rapid chloride penetration tests (RCPT) were performed in accordance with ASTM C1202 at different times. The tests were carried out with both plain (120/0 and 160/0) and fiber-reinforced mixtures (120/3.5, 160/2 and 160/3) in order to evaluate the permeability of the UHPFRC matrices without the test bias induced by the metallic fibers. The average results obtained from measurement on two specimens are shown in Figure 12.

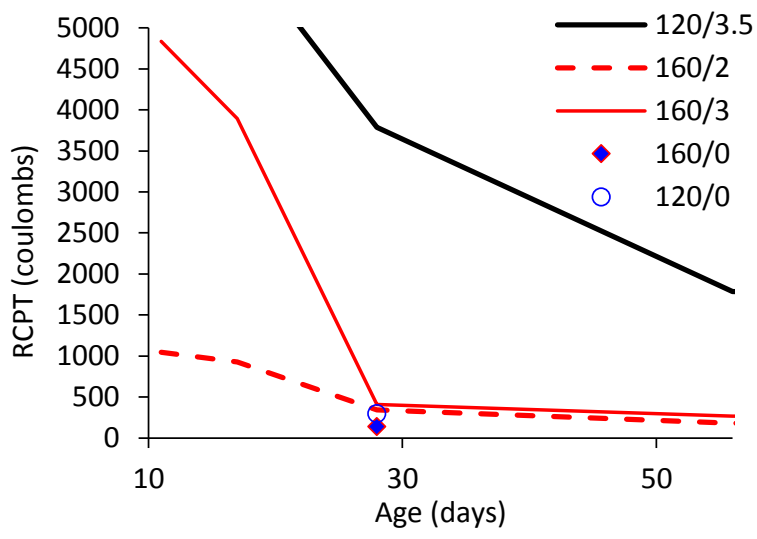

Fig. 12. Rapid chloride penetration tests (RCPT)

On the 11th day, it was impossible to measure the RTCP of UHPFRC 120/3.5 containing 3.5\% fiber with the standard test equipment due to its very high level and consequent excessive heating of the test equipment. On the same day, RTCP of the 160/3 mixture was in a range of 4500 coulombs and the 160/2 mixture in a range of 1000 coulombs. Unfortunately, the measurements on the mixes without fiber were not performed that day. At 28 days, the RCPT values yielded for the 120/0 and 160/0 mixtures are $300 \pm 6$ and $160 \pm 3$ coulombs, respectively. Comparatively, the early RCPT results were found to be significantly affected by the fiber content. Actually, it can be observed from the results presented in Figure 12 that the higher the fiber content, the higher the RCPT, ranging at 28 days from a few hundred coulombs for the plain mixtures up to more than $3800 \pm 300$ coulombs for the $120 / 3.5$ mixture. At 28 days, the RCPT recorded for the $160 / 2$ and $160 / 3$ mixtures had decreased to 340 and 410 coulombs respectively. It took 320 days for the RCTP of the $120 / 3.5$ mixture to decrease to a value of the order of $700 \pm 300$ coulombs.

The effect of steel fibers on the value of RTCP is the consequence of electrical conductivity of the fiber itself, and also of the existence of the interface between the hydrated cement paste and fibers. In the 2 groups of mixtures studied, 120 and 160 , only the quantity and the length of the added fibers varied. Consequently, there is an increase of the surface area of the interface between the steel fibers, the hydrated paste and sand grains, with the increase of fibre in the mixtures. The increase of density of this interface by progress of hydration decreases the RTCP. The larger interface in the mixtures containing more fiber need more time to be densified.

\subsection{Temperature rise in the repair}

As soon as the UHPFRC was poured, temperature inside the repairs was monitored using embedded thermocouples. The corresponding temperature development curves are shown in Figure 13. The temperature in repairs made with the 120/3.5 mixture never reached $60{ }^{\circ} \mathrm{C}$. Conversely, despite the absence of data in the first 24 hours due to recording problems, it is apparent that the maximum temperature reached inside the $160 / 3$ repair reached a peak that exceeded $80^{\circ} \mathrm{C}$. 


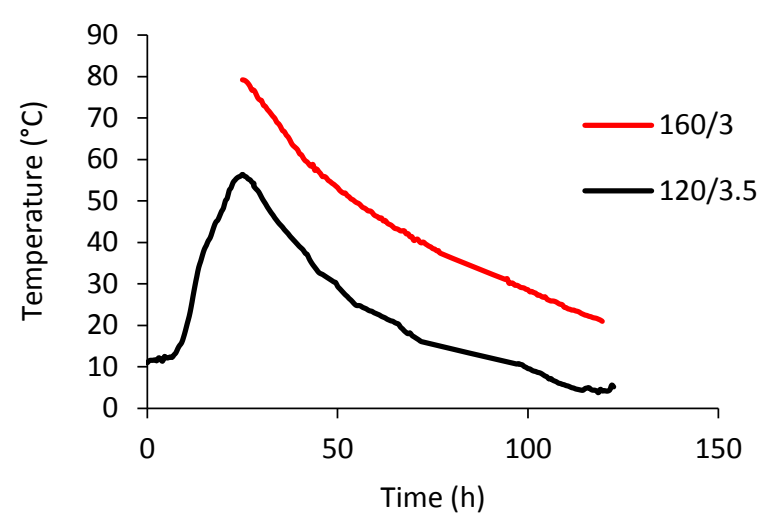

Fig.13. Monitoring of temperature inside the repairs from the time of placement

\section{Lock wall repair behaviour after a year}

Over a full navigation season following the repairs, the most exposed repair has already been struck five times (at least) by the hull of transiting ships. It must be mentioned here that while UHPFRC mixtures were used for the lock wall repairs, an HPC mixture was used for rebuilding the top of the wall (rounded coping in Figure 14), which was considered by the Seaway maintenance staff to be less at risk.

After five reported ship strikes, it can be seen in Figure 15 that the HPC coping is virtually destroyed, while the UHPFRC shows only limited, superficial damage, which is concentrated in areas where impacts occurred. Furthermore, as it can be seen in Figure 16, the damaged UHPFRC areas remain firmly attached to the structure, owing to a quite effective anchorage provided by the fibers.

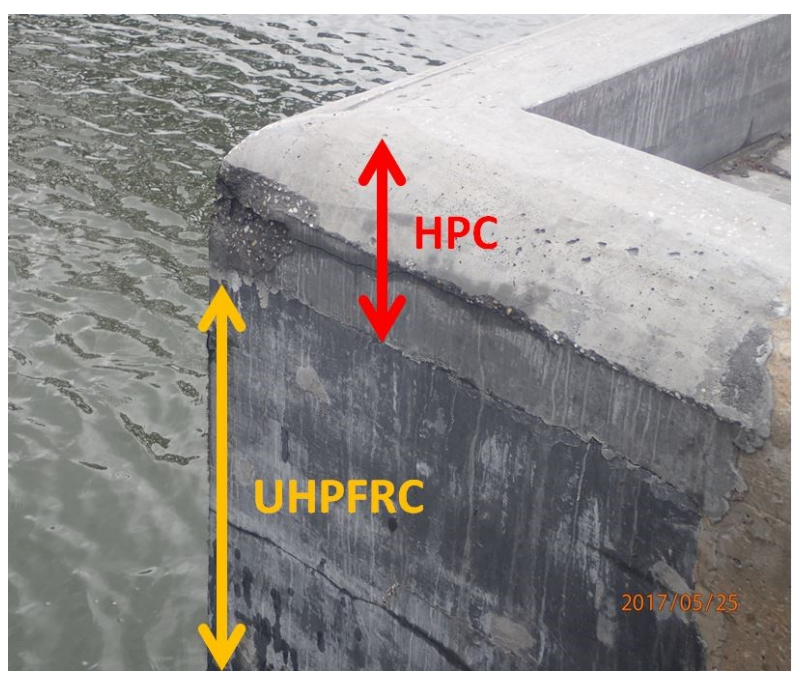

Fig. 14. Corner wall repair with UHPFRC, coped with HPC

The performance exhibited by the UHPFRC repairs after a full year in service has fully met the expectations. UHPFRCs can withstand the energy transmitted to walls upon impacts from the transiting vessels. The UHPFRC repairs have cracked, but it kept its overall integrity and stayed in place. Only a few small spalls, not exceeding $20 \mathrm{~mm}$ in size, detached from the repair surface.

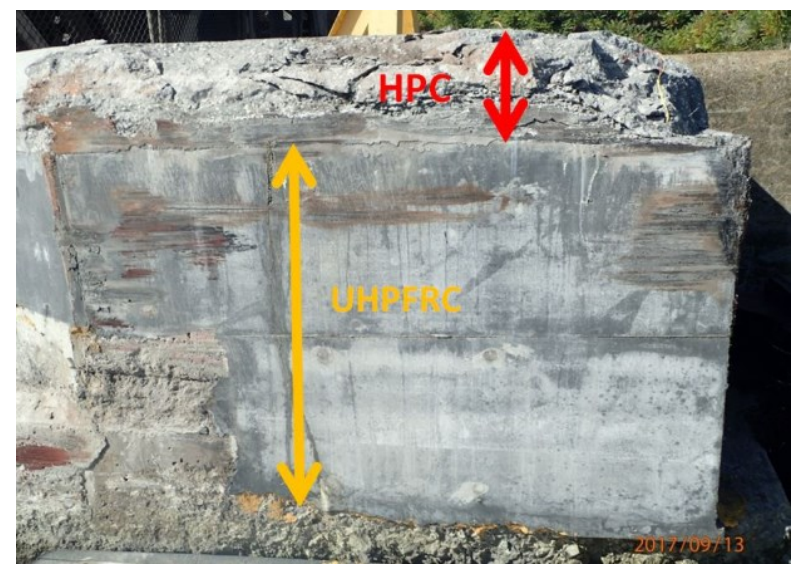

Fig. 15. Aspect of a corner wall repair after one year in service

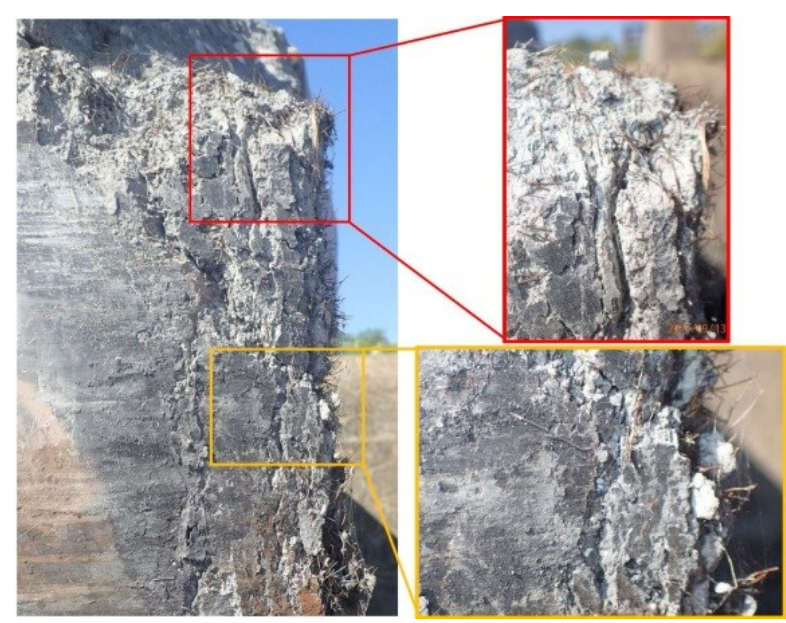

Fig. 16. Localized damage induced in a UHPFRC repair

\section{Discussion}

When comparing the two investigated UHPFRCs mechanical properties, the various strength data (compression, tension, flexure) of the 120/3.5 mixture are approximately 10 to $15 \%$ lower than those of the $160 / 3$ mixture, which is mainly attributed to the higher $\mathrm{w} / \mathrm{cm}$ [3], a lower cementitious materials content, and a resulting less dense fiber/paste interface [4]. In addition, more variation was found in the test results for the $120 / 3.5$, as revealed by the tensile strength test results range and standard deviation data. The larger observed variation is likely the consequence of introducing one more component into the 120/3.5 mixture, which is a second type of fiber. Moreover, increasing the total amount of fibers in the mixture decreases the workability of the concrete, which may affect in turn the resulting fiber distribution, ease of placement and degree of consolidation $[5,6]$. The effect of fiber orientation in the matrix is an important factor affecting the resulting tensile strength [5-8]. On the other hand, with adequately performed mixing and placement operations, the 120/3.5 mixture can develop a tensile strength comparable to that of the 160/3 mixture. 
Chloride permeability values yielded in RCPT experiments are found to be higher when the fiber content is higher for a given UHPFRC matrix. This is due to the electrical conductivity of the metal fibers and to the presence of fiber/paste interfaces in the fiberreinforced mixtures $[9,10]$. This interface is known to have a higher permeability than that of the cement paste [4]. The 28-day permeability of the $120 / 3.5$ mixture is observed to be quite high, but the UHPFRC matrix kept densifying over time as a result of continued hydration, and after one year, the RCTP of the mixture decreased to a much lower value, in the order of 700 coulombs.

Less autogenous shrinkage was measured on the $120 / 3.5$ mixture than on the $160 / 3$ mixture, which is mainly due to the higher $\mathrm{w} / \mathrm{cm}$ and lower cement paste content of the former [11]. The total shrinkage measured in drying conditions for the $120 / 3.5$ mixture is also less than that of the 160/3 mixture. On Figure 10, it can be observed that extended wet curing durations decrease the overall shrinkage of UHPFRC significantly. In fact, when extending the wet curing to 14 days, the shrinkage of the tested UHPFRCs has been reduced by approximately $1 / 3$. The observed reduction in total shrinkage is due to the extended hydration, as a result of changes in the pore structure and improved mechanical properties of the material. To reduce the risk of UHPFRC cracking due to shrinkage, prolonged wet curing appears to be quite beneficial. Nevertheless, a $3.5 \%$ fiber content in mixture $120 / 3.5$ and $3.0 \%$ fiber content in mixture 160/3 efficiently prevented cracking of UHPFRC for more than 28 days under severe conditions of restraint and drying. It clearly shows that the investigated UHPFRCs are resistant to shrinkage cracking. Based upon these results, there is probably no need for increasing the fiber contents beyond rates of addition of the order of 3.0 to $3.5 \%$.

While the mechanical and durability characteristics of the 160/3 mixture appears to be slightly better than those of the 120/3.5 mixture, the behaviour of in-situ repairs performed with these 2 mixtures is comparable. The maximum temperature (above $80^{\circ} \mathrm{C}$ ) reached in the $160 / 3$ mixture repair carries the risk of delayed ettringite formation (DEF) on the long run. Still, the risk is low given the high density and low permeability of the matrix, as well as the presence of supplementary cementing materials in the binder [12]. Besides, the maximum temperature reached in the 120/3.5 mixture, below $60{ }^{\circ} \mathrm{C}$, virtually eliminates the risk of DEF. Further research is needed to assess the actual risk of DEF in UHPFRCs. In the meantime, considering the rather small differences in mechanical properties and durability compared to those of $160 / 3$ mixture, the 120/3.5 mixture appears to be the most suitable choice for massive UHPFRC applications.

\section{Conclusion}

With the observed behaviour in the reported field experiments, it can be stated that UHPFRC can greatly improve the performance of repairs subject to repeated shocks and harsh weather. It is a material that opens up new possibilities in view of performing lasting repairs, in a range of applications and conditions. For an infrastructure manager such as the St. Lawrence Seaway, the use of this type of material for the repair of critical concrete elements will help improving operational efficiency and safety, and yield significant savings on the long-term.

In order to decrease the risk of UHPFRC cracking caused by shrinkage, extended wet curing is desirable. A 14-day wet curing period has been found to reduce the shrinkage of UHPFRC by $1 / 3$.

Increasing the fiber content beyond the values used in this study is not deemed necessary in view of ensuring shrinkage cracking resistance in service. In fact, even smaller rates of addition may be sufficient. Further research is needed to determine the fiber reinforcement dosage needed to prevent shrinkage cracking in UHPFRCs.

It is possible and desirable to use UHPFRC mixtures adapted to specific applications. For example, it will be preferable in some situations to design the material for lower mechanical strength and durability performance, in order to increase its workability and lower the maximum temperature reached during hydration.

Without the precious collaboration of the design engineers and contractor, it would not have been possible to successfully achieve this innovative repair project. The authors would like to thank the Maisonneuve Region engineering staff of the St. Lawrence Seaway Management Corporation involved in this project, as well as the staff of Martel Construction.

\section{References}

1. P. Richard, M. Cheyrezy, Composition of reactive powder concretes. Cement and Concrete Research 25, 1501-1511 (1995).

2. A. M. Soliman, M. L. Nehdi, Effects of shrinkage reducing admixture and wollastonite microfiber on early-age behavior of ultra-high performance concrete. Cement and Concrete Composites 46, 8189 (2014).

3. W. Piasta, B. Zarzycki, The effect of cement paste volume and w/c ratio on shrinkage strain, water absorption and compressive strength of high performance concrete. Construction and Building Materials 140, 395-402 (2017).

4. S. Abdallah, M. Fan, D. W. A. Rees, Bonding Mechanisms and Strength of Steel Fiber-Reinforced Cementitious Composites: Overview. Journal of Materials in Civil Engineering 30, (2018)

5. D.-Y. Yoo, S.-T. Kang, Y.-S. Yoon, Effect of fiber length and placement method on flexural behavior, tension-softening curve, and fiber distribution characteristics of UHPFRC. Construction and Building Materials 64, 67-81 (2014).

6. S.-T. Kang, J.-K. Kim, Investigation on the flexural behavior of UHPCC considering the effect of fiber orientation distribution. Construction and Building Materials 28, 57-65 (2012). 
7. L. F. M., Duque and B. Graybeal, Fiber orientation distribution and tensile mechanical response in UHPFRC. Mater. Struct. 55, 1-17 (2017).

8. D.-Y. Yoo, N. Banthia, Mechanical properties of ultra-high-performance fiber-reinforced concrete: A review. Cement and Concrete Composites 73, 267280 (2016).

9. V. Afroughsabet, L. Biolzi, P. J. M. Monteiro, The effect of steel and polypropylene fibers on the chloride diffusivity and drying shrinkage of highstrength concrete. Composites Part B: Engineering 139, 84-96 (2018).
10. P. Choi, K.-K. Yun, J. H. Yeon, Effects of mineral admixtures and steel fiber on rheology, strength, and chloride ion penetration resistance characteristics of wet-mix shotcrete mixtures containing crushed aggregates. Construction and Building Materials 142, 376-384 (2017).

11. E. Ghafari et al., Effect of supplementary cementitious materials on autogenous shrinkage of ultra-high performance concrete. Construction and Building Materials 127, 43-48 (2016).

12. Y. Amine, N. Leklou, O. Amiri, Effect of supplementary cementitious materials $(\mathrm{scm})$ on delayed ettringite formation in heat-cured concretes. Energy Procedia 139, 565-570 (2017). 